\title{
Erratum to: Primary and secondary prevention of atrial fibrillation with statins and polyunsaturated fatty acids: review of evidence and clinical relevance
}

Irene Savelieva • Antonios Kourliouros • John Camm

(C) Springer-Verlag 2010

Erratum to: Naunyn-Schmied Arch Pharmacol (2010)

381:207-219

10.1007/s00210-009-0468-y

The original version of this article unfortunately contained a mistake. The values in line 17 of the Meta-analyses section should be RR 0.96, 95\% CI, 0.87-1.07; $p=0.49$.

The online version of the original article can be found at http://dx.doi. org/10.1007/s00210-009-0468-y.

I. Savelieva $(\bowtie) \cdot$ A. Kourliouros $\cdot$ J. Camm

Division of Cardiac and Vascular Sciences,

St. George's University of London, Cranmer Terrace,

London SW17 0RE, UK

e-mail: isavelie@sgul.ac.uk 